\title{
Cardiac rehabilitation is safe and effective also in the elderly, but don't forget about drugs!
}

\author{
La Riabilitazione Cardiologica è sicura ed efficace negli anziani. Però ricordiamoci della terapia \\ farmacologica!
}

\author{
Donatella Del Sindaco1, Maria Denitza Tinti², Giovanni Pulignano², Stefano Tolone², \\ Giovanni Minardi2, Massimo Uguccioni2, Antonio Lax' \\ 1 Cardiology Unit, Nuovo Regina Margherita Hospital, Rome \\ 2 Cardiology 1/CCU, San Camillo Hospital, Rome, Italy
}

\begin{abstract}
In the setting of heart failure (HF) pharmacotherapy demonstrates a quantifiable improvement in exercise tolerance also in $\mathrm{HF}$ with preserved ejection fraction (HFpEF). For patients with HFpEF, often older, with higher prevalence of hypertension, diabetes mellitus, atrial fibrillation and other comorbidities, endpoints such as quality of life and functional capacity may be more clinically relevant. However several study show as the use of ACE-I and B-blocker were lesser than expected. Beta-blocker therapy is the keystone of pharmacotherapy of HF patients and exercise training is the essential core of rehabilitation programs, it is important to elucidate the relationship between these therapies. Exercise training improves the clinical status of HF, improving left ventricular ejection fraction and improving quality of life, but it is possible that b-blocker may attenuate exercise training adaptations. Despite this, possible adverse b-blocker effects are just presumed and not confirmed by published randomized clinical trials. Metanalysis suggests that b-blocker compared with placebo enhances improvements in cardiorespiratory performance in exercise training intervention. Despite these evidences, prescription of gold standard therapy and adherence are still suboptimal and should be a priority goal for all CR program.
\end{abstract}

Corresponding author: Donatella Del Sindaco, MD, Via G. Livraghi 1, 00152, Rome, Italy. Tel. +39.06.58446580. E-mail: donatelladelsindaco@virgilio.it

Key words: Heart failure; elderly; pharmacotherapy; exercise training. Parole chiave: Scompenso cardiaco; anziano; terapia farmacologica; esercizio fisico.

Received for publication: 11 April 2016

Accepted for publication: 18 April 2016

(C) Copyright D. Del Sindaco et al., 2015

Tipografia PI-ME Editrice, Italy

Monaldi Archives for Chest Disease Cardiac Series 2015; 84:737

doi: 10.4081/monaldi.2015.737

This article is distributed under the terms of the Creative Commons Attribution Noncommercial License (by-nc 4.0) which permits any noncommercial use, distribution, and reproduction in any medium, provided the original author(s) and source are credited.

\section{Riassunto}

Nell'ambito dei pazienti con scompenso cardiaco (SC) la terapia farmacologica permette di ottenere un miglioramento della tolleranza all'esercizio fisico anche nei pazienti con frazione di eiezione conservata. Questi pazienti spesso più anziani, con una più elevata incidenza di ipertensione, diabete mellito, fibrillazione atriale e comorbidità, endpoints quali qualità della vita e capacità funzionale dovrebbero risultare più clinicamente rilevanti. Tuttavia molti studi mostrano come l'utilizzo di ACE-I e Beta-bloccanti sia minore di quanto ci si aspetterebbe. Va evidenziato comunque come la terapia beta-bloccante costituisca il cardine della terapia farmacologica dello SC e come l'esercizio fisico sia il cuore dei programmi di riabilitazione, pertanto è importante valutarne le possibili interazioni. L'esercizio fisico migliora lo stato clinico dei pazienti con SC, ma è possibile che la terapia con Betabloccanti possa attenuare questi vantaggi. Tale assunto tuttavia rimane solo presunto e non confermato dai risultati dei trial pubblicati. Infatti una metanalisi suggerisce che la terapia Beta-bloccante, confrontata con il placebo, migliori la performance cardiorespiratoria nel gruppo sottoposto ad esercizio fisico. Malgrado tali evidenze, la prescrizione di una terapia medica ottimale e l'aderenza alla stessa rimangono ancora non ottimali e dovrebbe rappresentare un obiettivo primario per tutti i programmi di riabilitazione.

\section{Introduction}

Heart failure (HF) shows an age-related increasing prevalence as a consequence of the aging of the population as well as of the improved long-term survival of patients with ischemic heart disease and hypertension. Moreover, the clinical picture of older heart failure patients is heterogeneous and results from a complex interaction between cardiac disease and age-related changes, comorbidities, geriatric conditions and social issues. However, despite remarkable advances in diagnosis and therapy over the past decades, the prognosis of these patients remains poor, with high rates of hospitalization, readmission, and mortality. For these reasons, published HF RCTs have mainly focused on mortality and hospitalization endpoints, with a lesser attention to exercise tolerance and symptoms.

In HF with reduced ejection function (HFrEF), mortality endpoints do not always correlate well with change in exercise tolerance or quality of life - evident in examples of superior survival with limited or no symptom change [1], and symptomatic improvement without survival benefit [2]. 
Despite no significant treatment benefits in term of mortality or diastolic function improvement, pharmacotherapy have demonstrated a quantifiable improvement in exercise tolerance also in heart failure with preserved ejection fraction (HFpEF). Although nitrates are commonly prescribed for symptom relief in heart failure, a recent trial showed that HFpEF patients receiving isosorbide mononitrate were less active and did not have better quality of life or submaximal exercise capacity than did patients who received placebo [3]. There is still no clear evidence that heart rate reduction with ivabradine for improving symptoms in a HFpEF population characterized by exercise limitation [4].

As HFpEF patients are more often older, female, have a higher prevalence of hypertension, diabetes mellitus, atrial fibrillation and other concomitant comorbid conditions, endpoints such as quality of life and functional capacity may be more clinically relevant in this setting.

\section{Evidence-based prescriptions in CR}

The quality of care of older heart failure patients is often far to be satisfactory in clinical practice. Thus, the relative 'under use' of evidence based treatments largely appears to depend on the higher complexity and the lack of definite evidence on efficacy and safety of nonpharmacological and pharmacological treatments in the very elderly. Indeed, effective heart failure treatments such as angiotensin-converting enzyme (ACE) inhibitors, aldosterone antagonists, or betablockers may be considered not indicated in the elderly because of the high prevalence of renal vascular disease, renal impairment, diabetes, COPD and other various reasons. Multidrug therapy is a common feature in older patients, with multiple cardiovascular and noncardiovascular medications used for several associated diseases. Drug interactions and adverse reactions are common when multiple medications are prescribed for elderly patients. Thus the older heart failure population, which in fact comprises the majority of all patients, is in general less well studied, both experimentally and clinically, than younger populations. Older patients are generally underrepresented in randomized clinical trials because only a few of them have addressed the impact of therapy in patients aged more than 70-years-old and virtually none included patients aged more than 85 -years-old. These observations are likely dependent on the eligibility criteria of clinical trials, in which only patients with a poor LVEF and without significant comorbidities are included, whereas preserved systolic function and comorbidities frequently characterize elderly people. The main reason is that ACE-inhibitors, beta-blockers, angiotensin receptor antagonists and aldosterone antagonists have shown a benefit in terms of mortality and rehospitalization only in patients with a mean age of 63 and reduced LVEF, and the evidence on the effects in elderly patients and those with preserved systolic function are still limited. As a consequence, recent guidelines pointed out the lack of adequate knowledge on heart failure treatment in the elderly.

For similar reasons it's difficult to weight benefits of HF therapy in CR settings, as HF therapy implementation and uptitration to target doses is very inconstant among all trials and in the real world of clinical practice.

In the largest CR trail, the Heart Failure: A Controlled Trial Investigating Outcomes of Exercise Training (HF-ACTION) which enrolled 2331 patients with heart failure and reduced ejection fraction with a median age of 59 years (28\% were women, median follow-up 30.1 months), at 12 months of follow-up, ACE inhibitor or ARB use was 93.3\% in the usual care group versus $95.3 \%$ in the exercise training group, while beta-blocker use was $95 \%$ in the usual care group and $94 \%$ in the exercise training group [2].
In the HF-ACTION study, use of b-blockade was a baseline covariate predictor of survival, which is perhaps not surprising considering the link between peak oxygen consumption $\left(\mathrm{VO}_{2}\right)$ And mortality in $\mathrm{HF}$ patients. There was no significant interaction of exercise training with beta-blocker use.

Conversely, in a smaller CR study involving fifty-nine patients aged 60 and older with HFrEF HF drugs were prescribed far below previous statistics; in this study mean age was $70 \pm 5$ (range $60-80$ ), substantially greater than reported in most prior studies of CR in HFrEF, including HF-ACTION, and- also- the frequency of beta-blockers was relatively modest (10\% in all patients, with no significantly difference between groups) [5].

Likewise, in a trial studying the effect of exercise in 63 older patients with HFpEF (mean age $70 \pm 7$ years), both ACE-Inhibitors and betablockers were prescribed lesser than expected (for beta-blockers: $9 \%$ in CR group vs 35 in control group, $\mathrm{p}=0.02$ : for ACE-I $30 \%$ in CR group vs $24 \%$ in control group, $\mathrm{p}=0.44$ ) [6].

In particular settings, such as in CR after transcatheter aortic valve implantation (TAVI), implementing gold standard therapy is particularly challenging, mainly because of high rates of frailty and comorbidities among these patients.

In a study aimed at comparing CR program in octogenarians (mean age $83.3 \pm 3.6$ years) after a conventional surgical aortic valve replacement versus TAVI, beta-blockers were prescribed in $57 \%$ of patients while ACE-Inhibitors in 51.3\% [7].

Nevertheless, in previous experiences, basing on physiopathology, concern was raised about the effects of beta-blockers on exercise tolerance, especially regarding those with intrinsic sympathomimetic activity, for a smaller reduction in heart rate compared with b-blockers without ISA and a supposed inferior effect on exercise capacity.

\section{Beta-blockers and exercise}

During past decades, large observational studies, retrospective subgroup analyses and meta-analyses of clinical trials in systolic heart failure, and recently published randomized studies have provided data supporting the use of beta-blockers as a baseline therapy in heart failure in the elderly. Despite the available evidence about betablockers, this therapy is still less frequently used in elderly compared to younger patients. As beta-blocker therapy is the keystone of pharmacotherapy of HF patients and exercise training is the essential core of rehabilitation programs, it is important to elucidate the relationship between these therapies.

Exercise training improves the clinical status of HF patients by increasing peak $\mathrm{VO}_{2}$ [8], improving left ventricular ejection fraction (LVEF), lowering systemic brain natriuretic peptide (BNP) [8], and improving quality of life [9], but it is possible that b-blockers may attenuate exercise training adaptations.

Despite this, possible adverse b-blocker effects are just presumed and not confirmed by published randomized clinical trials and, if the effects on exercise capacity are better understood, many more patients eligible to use these drugs may assume them with better compliance.

A metanalysis from several trials has examined whether b-blockers weaken the effects of exercise training in HF patients, suggesting that b-blockade compared with placebo actually enhances improvements in cardiorespiratory performance in exercise training intervention; moreover, there was no difference between selective and nonselective bblockade as no drug of both classes appeared to attenuate exercise training-induced adaptations for HF patients.

Improvements in all outcome measures suggest that b-blockade, unless contraindicated by comorbidities, enhances exercise training- 
induced adaptations and unsupported suggestions that b-blockade worsens exercise capacity should not influence physicians' and patients' choices in pharmacotherapy [10].

In particular, with respect to elderly HF patients, in a subgroup of patients aged over 65 of the CIBIS-ELD study group undergone Doppler echocardiography and cardiopulmonary exercise testing before BB therapy and after 12 weeks, bisoprolol significantly reduced heart rate and systolic blood pressure at rest and during exercise (heart rate from $80.3 \pm 14.2 \mathrm{bpm}$ to $73.8 \pm 11.1 \mathrm{bpm}, \mathrm{p}=0.034$ and from $117.4 \pm 20.5 \mathrm{bpm}$ to $110.7 \pm 20.6 \mathrm{bpm}, \mathrm{p}=0.036$, respectively; systolic blood pressure from $132.5 \pm 24.0 \mathrm{mmHg}$ to $128.1 \pm 12.9 \mathrm{mmHg}$, $\mathrm{p}=0.043$, and from $186.7 \pm 20.6 \mathrm{mmHg}$ to $177.7 \pm 26.3 \mathrm{mmHg}$, $\mathrm{p}=0.030$ ), with sustained level of peak V02; also, according to Borg score, symptoms of breathlessness were significantly reduced (from 6.76 to $5.76, p=0.001$ ) [11].

\section{How to improve adherence?}

Basing on these data, it's mandatory to prevent withdrawal from beta-blocker treatment and, in general, from evidence-based therapies. Although evidences confirm that HF gold standard therapies improve exercise tolerance, low therapy adherence is still a key issue in CR.

Standard drug regimens for HF have become more complex in the last 15 years, due to the multiple therapeutic targets that exist and the need for routine symptomatic management.

Non-adherence to medication regimens is a common problem among patients with HF, and it limits the potential benefit of these drugs. Studies estimate that $30-60 \%$ of patients with HF do not assume medications as prescribed [12]. In fact, non-adherence is suggested to be the most common cause of preventable re-hospitalizations.

In the setting of $\mathrm{HF}$ adherence or compliance to medication is a component of self care. Self-care is a complex and multi-dimensional process, which also includes behaviors like diet and exercise, self-management, and seeking assistance when symptoms occur or weighing daily. Thus, self-care is influenced by a number of patient factors, such as knowledge of HF and its symptoms, previous experience, skills, coping strategies, cognitive status, and caregivers' support.

There are many potential reasons for the observed low levels of adherence, including the complexity of treatment regimens, side effects, cognitive impairment, poor understanding of the benefits of treatment and lack of disease knowledge, lack of support (eg, caregiver), difficulty in accessing physicians and pharmacies, confusion associated with taking medicines and polypharmacy [13].

In those patients a higher number of comorbid conditions and polypharmacy predict poor medication adherence. Having multiple conditions also decreases self-efficacy in performing specific self-care tasks such as medication taking [14].

Recognizing the weight of this management issue, the AACVPR/ACC/AHA Cardiac Rehabilitation/Secondary Prevention Performance Measures Writing Committee states that adherence to therapy is a major quality performance measures of CR programs, and should be enhanced by individual education and counseling about the importance of taking appropriate preventive medications ${ }^{15}$.

In this perspective, a rapid assessment of cognitive function and psychological status in older patients may lead to a more tailored follow-up and structured education in order to reduce the risk of non adherence to therapy, and, subsequently, worse self-care and related adverse consequences. Thus, in clinical practice, a structured follow-up of older patients, including written and verbally given care instructions, medication or dietary changes, caregiver surveillance and careful monitoring should be adopted (Table 1).
Table 1. How to facilitate adherence.

1. Initiate communication on the nature of the disease and need of therapy immediately after admission to hospital (time of maximum motivation to change);

2. Provide detailed information on the prescribed therapy and mode of follow-up after discharge directly to the patient;

3. Promote optimal contact between patient and operators health, by providing:

- adequate duration of the pre-dismissal interview,

- the first post-discharge control in the short term (30 days),

- adequate duration of follow-up visits,

- possibility of direct or dial-in the case of specific clinical problems;

4. Identify factors associated with non-adherence and use of specific tools occurs tack during follow-up as the morisky questionnaire;

5. Use the telephone recall especially in subjects at high risk.

In conclusion $\mathrm{HF}$ therapy plays a key role in enhancing exercise tolerance in HF patients, also in the elderly and in those with HFpEF. Despite these evidences, prescription of gold standard therapy is still low, particularly in frail patients and in those with multiple comorbidities. As a consequence, adherence is still suboptimal and should be a priority goal for all CR program. It is also evident that targeted clinical trials and rigorous observational studies are needed, aiming at developing more effective treatments and favoring the implementation of specific guidelines into clinical practice.

\section{References}

1. Bolger AP, Al-Nasser F. Beta-blockers for chronic heart failure: Surviving longer but feeling better? Int J Cardiol 2003;92:1-8.

2. O'Connor CM, Whellan DJ, Lee KL, et al. Efficacy and safety of exercise training in patients with chronic heart failure: HF-ACTION randomized controlled trial. JAMA 2009;301:1439-50.

3. Redfield MM, Anstrom KJ, Levine JA, et al. Isosorbide Mononitrate in heart failure with preserved ejection fraction. N Engl J Med 2015;373:2314-24.

4. Pal N, Sivaswamy N, Mahmod M, et al. Effect of selective heart rate slowing in heart failure with preserved ejection fraction. Circulation 2015;132:1719-25.

5. Brubaker PH, Moore JB, Stewart KP, et al. Endurance exercise training in older patients with heart failure: results from a randomized, controlled, single-blind trial. J Am Geriatr Soc 2009; 57:1982-9.

6. Kitzman DW, Brubaker PH, Morgan TM, et al. Exercise training in older patients with Heart failure and preserved ejection fraction: A randomized, controlled, single-blind trial. Circ Hear Fail 2010; 3:659-67.

7. Russo N, Compostella L, Tarantini G, et al. Cardiac rehabilitation after transcatheter versus surgical prosthetic valve implantation for aortic stenosis in the elderly. Eur J Prev Cardiol 2014; 21:1341-8.

8. Smart N, Marwick TH. Exercise training for patients with heart failure: a systematic review of factors that improve mortality and morbidity. Am J Med 2004;116:693-706.

9. Zuurmond W, Gootjes JRG, Tol-Verhagen C, et al. A simple standardized method for VAS measurements in terminally ill patients. J Palliat Med 2005;8 490-1. 
10. Ismail H, McFarlane J, Smart NA. Is exercise training beneficial for heart failure patients taking beta-adrenergic blockers? A Systematic review and meta-analysis. Congest Hear Fail 2013;19:61-9.

11. Dekleva M, Düngen H, Gelbrich G, et al. Beta blockers therapy is associated with improved left ventricular systolic function and sustained exercise capacity in elderly patients with heart failure. CIBIS-ELD sub-study. Aging Clin Exp Res 2012;24:675-81.

12. Setoguchi S, Choudhry NK, Levin R, et al. Temporal trends in adherence to cardiovascular medications in elderly patients after hospitalization for heart failure. Clin Pharmacol Ther 2010;88:548-54.
13. Bushnell CD, Olson DM, Zhao X, et al. Secondary preventive medication persistence and adherence 1 year after stroke. Neurology 2011;77:1182-90.

14. Mastromarino V, Casenghi M, Testa M, et al. Polypharmacy in heart failure patients. Curr Heart Fail Rep 2014;11:212-9.

15. Thomas RJ, King M, Lui K, et al. AACVPR/ACCF/AHA 2010 update: performance measures on cardiac rehabilitation for referral to cardiac rehabilitation/secondary prevention services: a report of the American Association of Cardiovascular and Pulmonary Rehabilitation and the American College. Circulation 2010;122:1342-50. 